\title{
Society Awareness and Acceptance on the Concepts of Water Sensitive Urban Drainage Design (WSUD) in Sarawak
}

\author{
Sheryl Den, Onni S. Selaman, and Darrien Y. S. Mah \\ Faculty of Engineering, Universiti Malaysia Sarawak \\ Date Received: ${ }^{\text {th }}$ August 2014 \\ Date Published: $1^{\text {st }}$ October 2014
}

\begin{abstract}
Water Sensitive Urban Design (WSUD) is a green approach to land development. Since introduced, the approach had been in practice in Peninsular Malaysia and Sabah, but not in favor yet in Sarawak. This study aims to identify Sarawak's society awareness and acceptance on the WSUD approach. Surveys are being distributed to respondents with engineering and non-engineering background. Scenarios involving five WSUD approaches, namely: (i) Swale Underground Drain; (ii) Rainwater Underground Storage; (iii) Dry Detention Pond; (iv) Porous Pavement; and (v) Infiltration Trench, are being presented to the respondents. At the initial stage of the survey, only 29\% of respondents with Civil Engineering background and 20\% of respondent without Civil Engineering background recognize the concept but after being exposed to some WSUD approaches throughout the survey $99 \%$ of both respondents with and without Civil Engineering background agrees that the approach is beneficial and should be encouraged in Sarawak.
\end{abstract}

Keywords: Green Infrastructure, MSMA, Social Survey, Stormwater Management, Urban Runoff

\section{INTRODUCTION}

W

ATER Sensitive Urban Design (WSUD) is the integration of urban design, site layout and building design, with constructed elements that can provide on-site stormwater a runoff pattern restored to near pre-development condition. It is a term used in Australia and is similar to Sustainable Urban Drainage (SUD) a term used in the United Kingdom and Commonwealth countries, Low Impact Development (LID) a term used in United States and Japan and Manual Saliran Mesra Alam (MSMA) or Urban Stormwater Management Manual for Malaysia, a term used in Malaysia.

WSUD is an approach to water management in urban areas with the concern on more sustainable design to urban environments by limiting the negative impacts of urban development in the total urban water cycle [1]. Conventional drainage system has been designed to provide the fastest possible transport of stormwater runoff out of catchments into a receiving water body [2]. With the increment of impervious areas due to urbanization, flash flood tends to occur. MSMA, WSUD and SUD concepts is a good approach to mitigate flash flood in urban areas. The approach also maintains and enhances water quality and encourages water conservation by promoting reuse of stormwater, recycling of effluent and regulated self-supply [3]. The concepts of WSUD are capital cost savings in which it can reduce capital costs that associate with drainage, and construction costs that associate with grading and tree clearing than the normal drainage [4]. WSUD applications include a range of applications: grassed or landscaped swales, infiltration trenches, bio-retention systems, gross pollutant traps, wetlands, sediment ponds, rainwater tanks for stormwater harvesting and reuse, grey water harvesting and reuse, rain gardens, rooftop greening, urban forests, porous pavements and aquifer recharge and reuse [5]. Hence, it could be said that the core of WSUD is sustainable stormwater management and also a green approach to land developments.

Even though MSMA has been more than ten years around the country since its first implementation by the Department of Irrigation and Drainage (DID) in year 2000, it is still a total stranger in the land of Sarawak. Therefore, this study is to create awareness to the local community towards WSUD and to assess the perception of local community on the concepts by conducting a survey in the rapidly developed Kuching and Samarahan areas.

S. Den is a Civil Engineering graduate from Universiti Malaysia Sarawak. She is currently an Engineer with Kian Sin Engineering Sdn. Bhd. Lot 981 , Section 66, Bintawa Industrial Estate, 93450 Kuching, Sarawak, Malaysia. (Tel: 6082-336835, Fax: 6082-345832, e-mail: sherylden91@ gmail.com).

O. S. Selaman is with the Department of Civil Engineering, Universiti Malaysia Sarawak, 94300 Kota Samarahan, Sarawak, Malaysia. (Tel: 082583281, Fax: 082-583409, e-mail: sosuhaiza@ feng.unimas.my).

D. Y. S. Mah is with the Department of Civil Engineering, Universiti Malaysia Sarawak, 94300 Kota Samarahan, Sarawak, Malaysia. (Tel: 082-583207, Fax: 082-583409, e-mail: ysmah@ feng.unimas.my). 


\section{UNIMAS e-Journal of Civil Engineering}

\section{RESEARCH METHODOLOGY}

Questionnaire is chosen as the method of data collection for this study. 800 questionnaires are distributed to the respondents. 400 questionnaires are distributed to respondents with Civil Engineering background and 400 questionnaires are distributed to respondents without Civil Engineering background.

Respondents with Civil Engineering background are the $1^{\text {st }}$ to $4^{\text {th }}$ year Civil Engineering undergraduates from Universiti Malaysia Sarawak (UNIMAS), engineers with Jabatan Kerja Raya (JKR), Sarawak Land Consolidation and Rehabilitation Authority (SALCRA) and SALCRA Jaya Sdn. Bhd. Whereas, respondents without Civil Engineering background are the public communities, undergraduates of Universiti Malaysia Sarawak other than the Department of Civil Engineering, general employees from JKR, SALCRA, SALCRA JAYA Sdn. Bhd. and Research Agricultural Centre in Semenggok.

The questionnaires are elaborated into different categories. Each question from the questionnaire is regarding the acceptance of society towards the concepts of WSUD in Sarawak to correspond responses. Besides, the questionnaire is designed in such a way to help the respondents to understand the concepts of WSUD. Sample of questionnaire is attached in the Appendix. Spreadsheet of Microsoft Excel is utilized to analyze the survey data.

\section{RESULTS, ANALYSIS AND DISCUSSION}

\section{RATE OF SOCIETY RESPONSE ON THE QUESTIONNAIRE}

The study receives high responses from the society as indicated by the number of completed questionnaires received - 353 (88\%) from respondents with Civil Engineering background and 366 (92\%) from respondents without Civil Engineering background.

\section{QUESTION 1 - SOCIETY RECOGNITION OF WSUD, SUD AND MSMA}

Question 1 from the questionnaire is to identify whether the population from different background which are respondents with and without Civil Engineering background could recognize the existence of the terms WSUD, SUD and MSMA.

From 353 respondents with Civil Engineering background, only 101 (28.6\%) of them recognize the term. The result suggests that respondents are less aware of the existence of WSUD, SUD and MSMA even when the respondents have a history of Civil Engineering background. As for respondents without Civil Engineering background, majority of them 294 out of $366(80.3 \%)$ have not heard of the term. Data suggest that this category has even lower recognition of the mentioned terms than the previous category.

Majority of the respondents have never heard of WSUD, SUD as well as MSMA whereas this Urban Stormwater Management Manual design guideline have been around for a decade in Malaysia and has been widely accepted in Peninsular Malaysia and Sabah. This is because there is a lack of stormwater management projects being built or designed in accordance with this guideline in Sarawak as compared to in Peninsular Malaysia and Sabah. This has led to lower recognition of the terms among the respondents, particularly so to those without Civil Engineering background.

\section{QUESTION 3 - PREFERABLE EXECUTION LOCATION OF WSUD APPROACHES}

Question 3 is intended to determine whether respondents prefer the concepts of WSUD to be executed. The locations of execution provided are inside the building, within the house compound or garden or backyard; and outside the property or road or empty land spaces.

The result shows that the most preferred place is outside the house which is to be place at the road or empty land spaces. There are $209(59.2 \%)$ respondents with Civil Engineering background and 228 (62.3\%) respondents without Civil Engineering background who mark "Outside your property/ road/ empty spaces" the highest preferred locations. 120 (34\%) respondents with Civil Engineering background and 90 (24.6\%) respondents without Civil Engineering background have chosen the garden or backyard or within the house compound as the preferable location for WSUD approach.

The public seems to have a concept of WSUD is more suitable to be at the roads or empty land spaces. Contradictorily, collective measures applied within houses or gardens or courtyards over a region are more effective as control-at-source WSUD approach [6], for obvious reason - high number of domestic houses than scarce empty lands in urban areas. 
Question 2 from the questionnaire is to introduce the concept of WSUD, SUD and MSMA to the community. Respondents are being asked whether they prefer the conventional system of concrete drain or the WSUD approach of Swale Underground Drain.

The results show that $94 \%$ of respondents with Civil Engineering background choose swale; while $6 \%$ prefer the existing system of concrete drain. The group without Civil Engineering background registers $92 \%$ respondents choosing swale, and $8 \%$ respondents preferring the existing system. The data also indicate that more respondents without Civil Engineering background prefer the WSUD approach of Swale Underground Drain than the existing drain.

\section{QUESTION 4 and QUESTION 5 - APPLICATION OF RAINWATER UNDERGROUND STORAGE}

The application of Rainwater Underground Storage at Main Bazaar area is introduced to the community in Sarawak in Question 4. There are two different types of implementation methods proposed in this section which are: (i) proposing along Jalan Carpenter and Jalan Ewe Hai (Option 1), such measure requires more excavation of road; and (ii) proposing a Rainwater Underground Storage only at the junction that involves less excavation of road (Option 2). The question is intended to identify the preferable method of installing Rainwater Underground Storage at Main Bazaar.

Option 1 in Question 4 has more excavation of road. However, Option 2 has less excavation of road. The results show that the respondents prefer Option 2 rather than Option 1. There are $227(64.3 \%)$ respondents who have selected Option 2 while $100(28.3 \%)$ respondents have selected Option 1 and $26(7.4 \%)$ respondents from the group of respondents with Civil Engineering background dislike both ideas. As for respondents without Civil Engineering background have a total of 231 $(63.1 \%)$ respondents who choose Option 2, while 90 (24.6\%) choose Option 1 and $45(12.3 \%)$ of them do not agree with both ideas.

In the engineering mindset, it requires less cost to the idea of Rainwater Underground Storage constructed only at the junction than along Jalan Carpenter. However, without thinking engineering, it is less traffic congestion during construction of the proposed Rainwater Underground Storage.

Question 5 from the questionnaire is introducing another application of Rainwater Underground Storage that is suggested to be implemented in Padungan Area, Kuching City. Another two different types of installation methods are being proposed which are: (i) along the main road of Jalan Padungan, the target area is the main road which subjected to heavy traffic; and (ii) along the back lane of shophouses located at Jalan Padungan. This back lane is used as parking lots. This section is to introduce the application of Rainwater Underground Storage to the community in Sarawak which intended to identify the preferable methods of installing Rainwater Underground Storage at Jalan Padungan.

In Question 5, Approach A is along the busy main road that has more traffic. Approach B is along the back lane which is used as parking lots. The survey shows that both groups prefer Approach B rather than Approach A. There are 280 (79.3\%) respondents who have selected Approach B while 38 (10.8\%) respondents have selected Approach A and 35 (9.9\%) respondents dislike both ideas from the group of respondents with Civil Engineering background. Respondents without Civil Engineering background have 245 (66.9\%) respondents who choose Approach B, 75 (20.5\%) choose Approach A and 46 $(12.6 \%)$ of them do not agreed with both ideas.

It is understandable that the proposed Rainwater Underground Storage along the back lane of Jalan Padungan are easy to construct as compared to have the storage system implemented along the main road with busy traffic.

\section{QUESTION 6 and QUESTION 7 - APPLICATION OF DRY DETENTION POND}

Another WSUD approach is Dry Detention Pond which is to slow down the stormwater runoff from large precipitation events. Question 6 and Question 7 introduce this application to the respondents. Two examples of application of Dry Detention Pond are given in the Questionnaire. In Question 6, Dry Detention Pond is suggested to be installed at the campus field. This question is intended to determine the acceptance of society on the idea of Dry Detention Pond to be executed in Sarawak. In Question 7, the Dry Detention Pond is suggested to be implemented in the roundabout to soak away stormwater from roads. This is intended to identify the acceptance of community in Sarawak on suggestion to convert roundabout to Dry Detention Pond.

The results from Question 6 indicate that $183(51.8 \%)$ respondents with Civil Engineering background agree to the idea of Dry Detention Pond at the campus field while 170 (48.2\%) respondents do not agreed. As for the group without Civil Engineering background, 258 (70.5\%) choose the idea while $108(29.5 \%)$ disagree. As for Question 7, the survey shows that $306(86.7 \%)$ of respondents who choose application of Dry Detention Pond at the roundabout while $47(13.3 \%)$ dislike the idea from respondents with Civil Engineering background. Whereas, 300 (82\%) respondents from the group of respondents 


\section{UNIMAS e-Journal of Civil Engineering}

without Civil Engineering background choose the approach while 66 (18\%) do not agreed.

The results from Question 6 and 7, when compared demonstrate that there are more respondents from both groups choosing Dry Detention pond to be installed at the roundabout than at the field. Therefore, the society prefers the application of Dry Detention Pond to be implemented at the roundabout as the stormwater drainage system. There are many roundabouts in Kuching that can be installed with Dry Detention pond and mostly has a large size of roundabout, thus this can help to manage urban runoff properly during heavy rainfall events. Besides, having such function added to a roundabout does not interrupt the traffic.

\section{QUESTION 8 - APPLICATION OF POROUS PAVEMENT}

Question 8 from the Questionnaire introduces another WSUD approach which is Porous Pavement to the respondents. Porous Pavement is suggested as road surface and temporary storage that allows the stormwater to seep into the ground. The objective of this question is to determine the acceptance of community in Sarawak on the idea of applying Porous Pavement.

There are $283(80.2 \%)$ respondents who have agreed to the idea of Porous Pavement while 70 (19.8\%) respondents do not agreed from the group of respondents with Civil Engineering background. On the other part, group of respondents without Civil Engineering background has shown that there are $309(84.4 \%)$ respondents have chosen the idea of the Porous pavement while $57(15.6 \%)$ respondents do not agreed. This data represent that both groups has agreed with the idea of Porous Pavement. Therefore, Porous Pavement is suggested in low traffic roads and parking areas as the system can manage the stormwater by eliminating standing water on pavement more effectively.

\section{QUESTION 9 - APPLICATION OF INFILTRATION TRENCH}

In Question 9, application of Infiltration Trench is introduced to the community in Sarawak. It is suggested to have road kerb converted to Infiltration Trench to store rain water. The purpose of this question is to determine understanding and acceptance by the respondents regarding the concepts of WSUD by convergence of existing road kerb to Infiltration Trench.

The results show that $338(95.8 \%)$ respondents with Civil Engineering background choose the application of Infiltration Trench while $15(4.2 \%)$ dislike the idea. Group of respondents without Civil Engineering background has 349 (95.4\%) respondents who choose the application while 17 (4.6\%) respondents do not agreed with the approach. This data represent that both groups of respondents has agreed with the idea of converting road kerb into Infiltration Trench and to store stormwater.

\section{QUESTION 10 - RESPONSE TO WSUD APPROACH}

Question 10 is to identify the respondents' consideration on WSUD approaches after seeing all the examples, whether they found it beneficial and should be encouraged in Sarawak or it is nonsense and should be abandoned. 99\% of the respondents agree that WSUD approach is beneficial and should be encouraged in Sarawak while $1 \%$ does not, by both groups of respondents.

The concepts of WSUD have been introduced to the respondents throughout the survey. Almost all the respondents from both groups with different background can understand the concepts after going through the examples of WSUD in the questionnaire. Therefore, public acceptance of the concepts of WSUD can be concluded as high.

\section{QUESTION 11 - ACCEPTANCE OF SOCIETY ON WSUD CONCEPT}

Question 11 discusses the preference of respondents on either existing drainage or WSUD approach. In this question, respondents are given the choice to select the preferable system for urban drainage system. From the collected data, the result shows that there are $99 \%$ respondents who choose WSUD approach while 1\% prefers the existing system from respondents with Civil Engineering background. As for the group without Civil Engineering background, 97\% of respondents choose WSUD approach while 3\% prefer the existing system. The data show that both groups are accepting WSUD approach as a new way to drainage system.

\section{CONCLUSION}

Questionnaires are distributed in Kuching and Samarahan areas, which representing the most populated, socially and economically advanced hubs in the Southern region. The survey shows that at first almost all of the respondents with and without Civil Engineering background are still lacking of recognition in WSUD. The respondents have been exposed to five examples of WSUD applications, which are Swale Underground Drain, Rainwater Underground Storage, Dry Detention 


\section{UNIMAS e-Journal of Civil Engineering}

Pond, Porous Pavement and Infiltration Trench. These WSUD approaches are suggested to be implemented in Kuching area and needed opinions from respondents. Results obtained show that the respondents generally are in high favor of Infiltration Trench, Swale Underground Drain and Porous Pavement.

Results on Rainwater Underground Storage proposed to be implemented at Main Bazaar, Kuching indicate that most of the respondents prefer Rainwater Underground Storage to be implemented only at the junction of Main Bazaar than to be installed along the road. Another opinion from the respondents is that they prefer Rainwater Underground Storage to be installed along the back lane of Jalan Padungan, Kuching than to be installed along the hectic Jalan Padungan.

As for the Dry Detention Pond, both groups of respondents agree that it could be executed at both campus field and at roundabout. If compared between the two locations execution, both groups are in agreement that Dry Detention Pond at roundabout is more practical than at campus field.

At the end of the questionnaire survey, after the respondents go through the examples of WSUD approaches, the respondents generally agree that WSUD approach is beneficial and should be encouraged in Sarawak. Most respondents also prefer WSUD approach than existing system.

\section{REFERENCES}

[1] C. L. Baraclough, and W. P. Lucey. (2008). Water Sensitive Urban Design. Canada Mortgage and Housing Corporation. Retrieved from http://www.cmhc-schl.gc.ca/en/inpr/bude/himu/coedar/upload/OAA WaterSensitiveUrbanDesign EN july11 w.pdf

[2] N.A. Zakaria, A. Ab. Ghani, R. Abdullah, L.M. Sidek, A. H. Kassim, and A. Ainan. (n.d.). MSMA - A New Urban Stormwater Management Manual for Malaysia. Advances in hydro Science and Engineering, Volume VI. Retrieved from http://redac.eng.usm.my/html/publish/2004 06.pdf

[3] S. Beecham. (2003). Water Sensitive Urban Drainage.A Technological Assessment. Retrieved from http://epress.lib.uts.edu.au/research/bitstream/handle/10453/5839/2003001316.pdf?sequence=1

[4] Bayside City Council. (n.d.) Water Sensitive Urban Design. Retrieved from http://www.bayside.vic.gov.au

[5] Melbourne Water. (2014). WSUD Approach. Retrieved from : http://www.melbournewater.com.au/Planning-and-building/Stormwatermanagement/Water-Sensitive-Urban-Design/Pages/The-WSUD-approach.aspx

[6] A. A. Abd. Manap. (2009). Efficiency of Swale and Dry Pond for Stormwater Management. Master Thesis. Retrieved from http://eprints.usm.my/15513/1/EFFICIENCY_OF_SWALE_AND_DRY_POND.pdf

\section{APPENDIX}

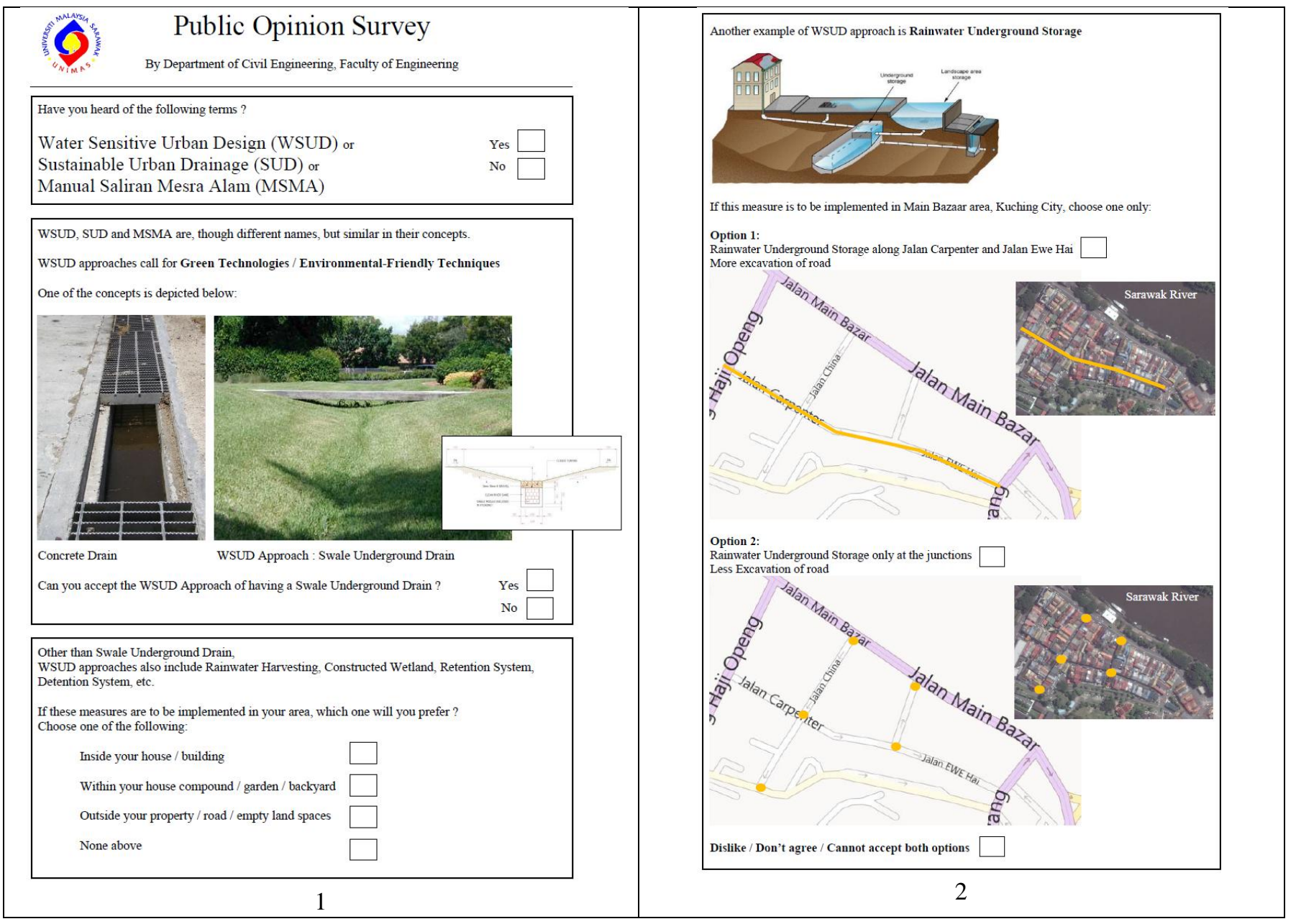




\section{UNIMAS e-Journal of Civil Engineering}

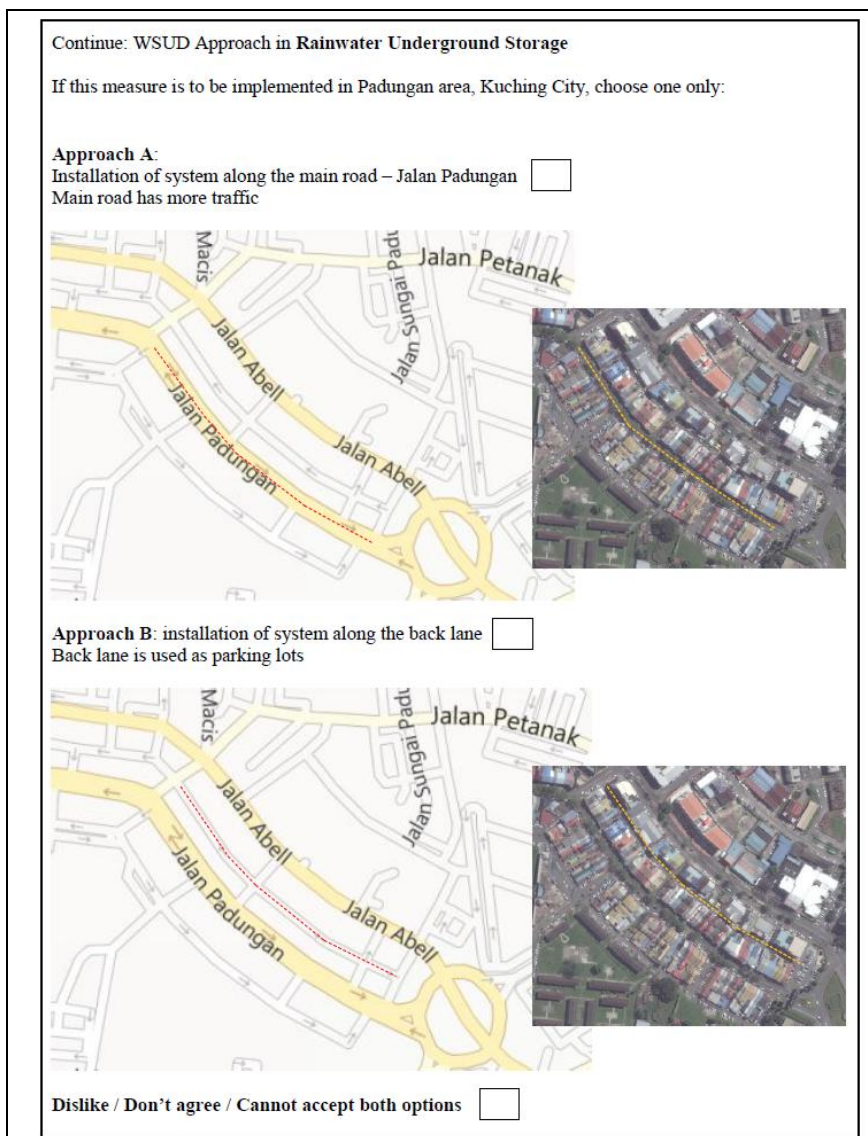

3
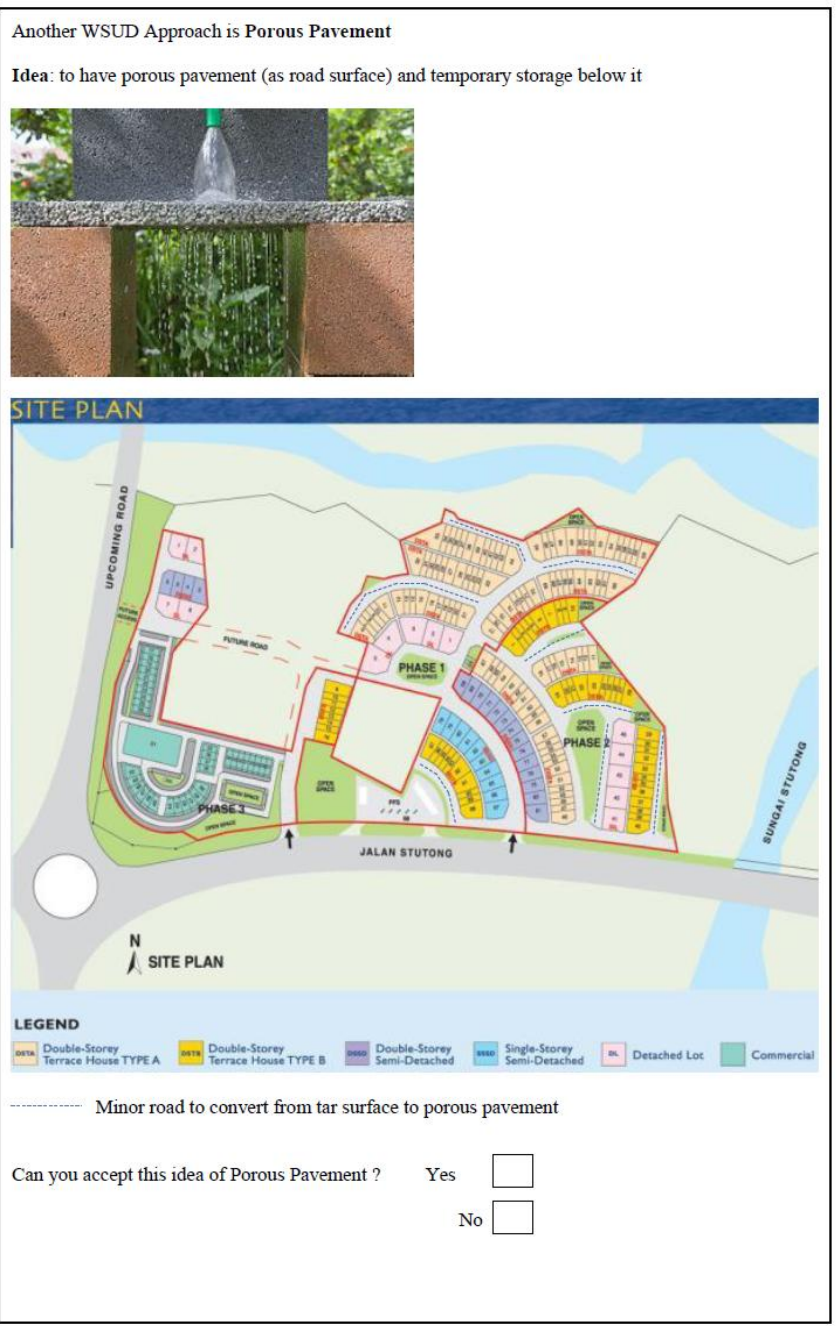

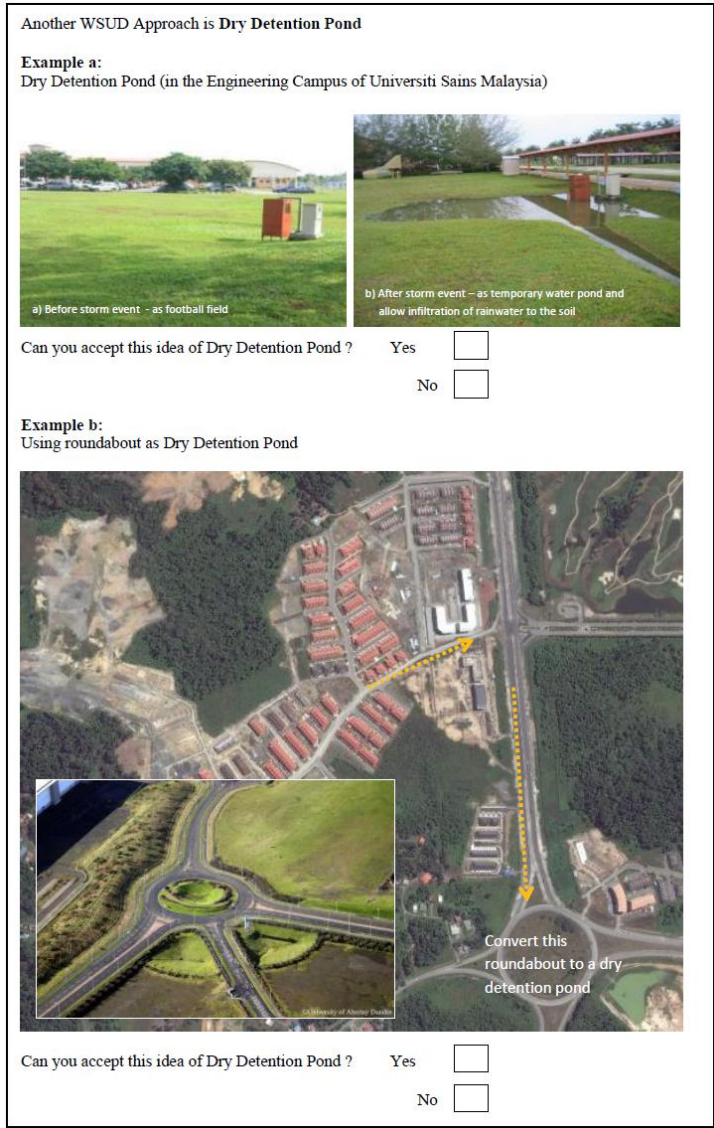

4

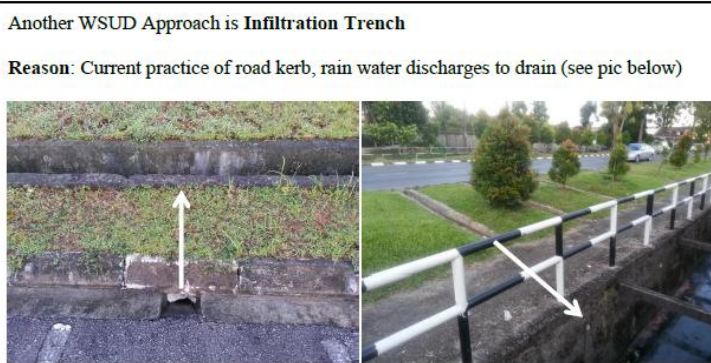

Idea: to have the road kerb converts to infiltration trench to store the rain water
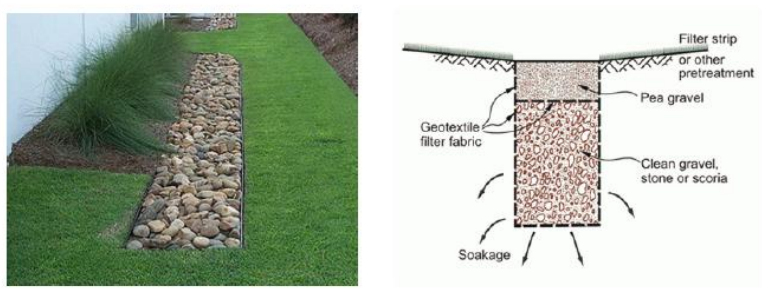

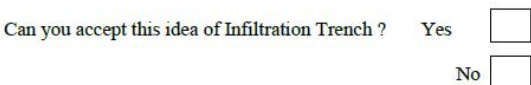

\section{After seeing all the examples above, do you think :}

WSUD Approach is beneficial \& should be encouraged in Sarawak

WSUD Approach is nonsense \& should be abandoned

If you are given a choice, do you prefer

Existing system

WSUD Approach 